\title{
Synthesis and characterization of castor oil based polyurethane-polyacrylonitrile interpenetrating polymer networks ${ }^{\dagger}$
}

\author{
P MALLU, SIDDARAMAIAH ${ }^{*}$ and R SOMASHEKAR \\ Department of Polymer Science and Technology, SJ College of Engineering, Mysore 570 006, India \\ ${ }^{\ddagger}$ Department of Studies in Physics, University of Mysore, Mysore 570 006, India
}

\begin{abstract}
A series of interpenetrating polymer networks (IPNs) of castor oil based polyurethane/polyacrylonitrile (PU/PAN: 80/20, 60/40, 50/50, 40/60 and 20/80) were synthesized by condensation reaction of castor oil with methylene diisocyanate and acrylonitrile, employing benzoyl peroxide (BPO) and ethylene glycol dimethylacrylate (EGDM) as initiator and crosslinkers respectively. The physical, chemical, optical and some of the mechanical properties of PU/PAN were studied. Phase stabilization in IPNs was investigated by wide angle X-ray (WAXS) profile analysis. Variation of crystal size distribution was studied in these polymer networks.
\end{abstract}

Keywords. Castor oil; MDI; interpenetrating; mechanical; crystal size; strain.

\section{Introduction}

Interpenetrating polymer networks (IPNs) constitute a group of polymer composite materials possessing unique properties which are related to their method of synthesis (Sperling 1981). IPNs typically consist of a flexible elastomer and one or more rigid, high modulus component.

Considerable work has been reported (Frisch et al 1969, 1981; Hourston and Zia 1984; Patel et al 1988), on the synthesis of IPNs based on PU obtained from castor oil, polyesters, and diisocyanates. The effect of the isocyanate/hydroxy ratio, crosslink-density, and vinyl monomer content on the various properties have been reported. In this paper we report the synthesis and characterization of IPNs of castor oil based polyurethane and polyacrylonitrile. Crystal imperfection parameters of these IPNs using X-ray profile analysis lead to a significant structure-property relation. Variation of crystal size distribution in these materials has also been reported (Patel and Suthar 1987). From literature search, it has been found that PU/PAN IPN system was not studied by WAXS. In continuation to our previous publication (Siddaramaiah et al 1998), on PU/PS characterization from WAXS and thermal behaviour, the new series of PU/PAN of materials have been reported in this article.

\footnotetext{
*Author for correspondence

${ }^{\dagger}$ Paper presented at the 5th IUMRS ICA98, October 1998, Bangalore
}

\section{Experimental}

\subsection{Materials}

Castor oil was obtained from the local market, its characteristic properties such as hydroxyl no. 160 to 168 , and acid value 2.45 and isocyanate equivalent 330 , were estimated according to the literature (Naughton 1974). Methylene diisocyanate (MDI) from Fluka, Switzerland, ethylene glycol dimethylacrylate (EGDM) and benzoyl peroxide from Aldrich, USA, and stannous octoate (sigma) were used. Acrylonitrile (AN) monomer from Schuchardt M, Germany was freed from stabilizer prior to use.

\subsection{Prepolymer preparations}

The prepolymer was prepared by reacting one mole castor oil with 2 moles of MDI using stannous octoate as the catalyst. In a typical reaction, $63.6 \mathrm{~g}$ castor oil, $26.4 \mathrm{~g}$ of MDI, along with few drops of stannous octoate were placed in a round bottom flask fitted with a stirrer. The reaction was carried out at room temperature $\left(28 \pm 1^{\circ} \mathrm{C}\right)$ with continuous stirring. Stirring was carried out for $15-$ 20 min to complete the reaction such that terminated isocyanate polyurethane prepolymer was obtained as a thick syrup.

2.2a Synthesis of PU-PAN interpenetrating polymer networks: The required quantities of urethane prepolymer acrylonitrile, EGDM ( $0.5 \%$ based acrylonitrile used), and benzoyl peroxide $(0.5 \%)$ were placed in a roundbottom flask fitted with a mechanical stirrer. The mixture 
was stirred at room temperature for $10-15 \mathrm{~min}$ to form a uniform mixture. Compositions having higher amounts of prepolymer were highly viscous and the air entrapped during mixture was removed by applying vacuum. On the other hand, compositions rich in acrylonitrile were heated at $70^{\circ} \mathrm{C}$ (to initiate the polymerization of $\mathrm{AN}$ ) for different intervals of time until an optimum viscosity was obtained. If the mixture was heated for a shorter period, then gelling took place, and the viscosity was so low that it led to the formation of molds in the sheet.

2.2b Preparation of mold: Two toughened glass plates of $215 \times 290 \mathrm{~mm}^{2}$ size were cleaned and sprayed with the releasing agent (silicone spray). A PVC gasket of diameter $3 \mathrm{~mm}$ was placed in between the plates that were held together using steel clamps. One side of the glass plate was kept open for pouring the syrup. Approximately $100 \mathrm{~g}$ of the syrup was added into the mold and the opening was closed using a metal plate followed by clamps. The filled mold was kept in a preheated circulating air oven maintained at $70^{\circ} \mathrm{C}$. It was held at this temperature for $24 \mathrm{~h}$ and $120^{\circ} \mathrm{C}$ for $4 \mathrm{~h}$. The sheet thus formed, was cooled slowly and removed from the mold.

\section{Characterization and testing}

The IPNs were characterized according to the ASTM standard specification. Density was determined by the displacement method according to ASTM-D-792-86, ASTM D-676-58 J for shore-A hardness. The optical properties were measured using a Suga Test, Hazemeter (Japan) using dust and grease free film of IPNs as per ASTM D1003. Mechanical properties were measured using Hounsfield Universal Testing Machine Model (UTM) M $50 \mathrm{~K}$ (ASTM-D 638).

Intensity data for profile analysis was collected on a STOE/STADI-P powder diffractometer with BraggBrentano geometry (fine focus setting) with germanium monochromated $\mathrm{CuK}_{1}(\lambda=1.54056)$ radiation in $2 \theta$ range 3 to $45^{\circ}$ at intervals of $0.02^{\circ}$ using a curved position sensitive detector in the transmission mode. Figure 1 shows the X-ray pattern for various samples (IPN1IPN5).

\subsection{Profile analysis}

It is to be emphasized here that the X-ray profile broadening observed in these polymers (figure 1) is due to both (i) crystal size and (ii) lattice distortion (strain) present in the materials. Scherrer equation is an empirical equation which does not consider the strain present in the samples and hence, leads to an over-estimated value. There are multiple order methods using Fourier analysis and also other techniques implying FWHM technique. Since we do not observe two orders of X-ray reflection from the same Bragg plane, we have to use single order method.

We have used generally applicable one-dimensional model based on distortion of the lattice (Somashekar and Somashekarappa 1997) to obtain the average microstructural parameters like crystal size and strain along different directions of the lattice employing individual $(h k l)$ reflection. The corrected experimental X-ray profile was matched with the simulated profile using the equations

$$
I(s)=I_{N-1}(s)+I_{N}^{\prime \prime}(s),
$$

where,

$$
\begin{aligned}
I_{N}(s)= & 2 * \operatorname{Re}\left[\left(C_{1}-I^{N+1}\right) /(1-I)+\right. \\
& \left.I v / d(1-I)^{2}\left\{I^{N}(N(1-I)+1)-1\right\}\right]^{-1} .
\end{aligned}
$$

Here $v=2 i a^{2} s+d$ and $I=I_{1}(s)=\exp \left(-a^{2} s^{2}+i d s\right)$ with $a^{2}=w^{2} / 2$. $I_{N}^{\prime \prime}(s)$ is the modified intensity for the probability peak centre at $d\left(=n d_{h k l}\right)$ and it has been shown that

$$
\begin{aligned}
I_{N}^{1}(s)= & \left(2 a_{N} / D \pi^{1 / 2}\right) \exp (i d N s)\left[1-a_{N} s\left\{2 D\left(a_{N} s\right)+\right.\right. \\
& \left.\left.i \pi^{1 / 2} \exp \left(-a_{N}^{2} s^{2}\right)\right\}\right]
\end{aligned}
$$

where $a_{N}^{2}=N w^{2} / 2$ and $D\left(a_{N} s\right)$ is Dawson's integral or the error function with purely complex argument and can be easily computed. $N$ is the number of unit cells counted in a direction perpendicular to the $(h k l)$ Bragg plane. The experimental profile between $s_{0}$ and $s_{0}+s_{0} / 2$ (or $s_{0}$ and $s_{0}+B / 2 d$, if there is a truncation of the profile, $B<1$ ) is matched with corresponding simulated order of reflection between $s_{0}$ and $s_{0}+s_{0} / 2$ (or $s_{0}$ and $s_{0}+B / 2 d$ ) using a onedimensional distorted model for various values of $N$ and $g$ to minimize the difference between calculated and experimental normalized intensity values. SIMPLEX, a multidimensional algorithm (Press et al 1986) was used for minimization. Table 3 lists the values of $N$ and $g$, with their standard deviations obtained for the observed two $\mathrm{X}$-ray reflections. The estimated enthalpy $\alpha^{*}\left(=N^{1 / 2} g\right)$ (Hindeleh and Hosemann 1991) physically implies that the growth of the crystals in a particular material is controlled appreciably by the value of $g$ in the net plane structure.

\section{Results and discussion}

\subsection{Physical properties}

All IPNs were synthesized as tough films from golden yellow to yellow colour. The IPNs are almost insoluble and their densities are heavier than water. The densities of IPNs range from 1.075 to $1.168 \mathrm{~g} / \mathrm{cc}$. Density of IPNs increases with increase in PAN (because PAN density is $>1$ ) composition. The densities of all IPNs are given in table 1 along with the composition of individual IPNs. 

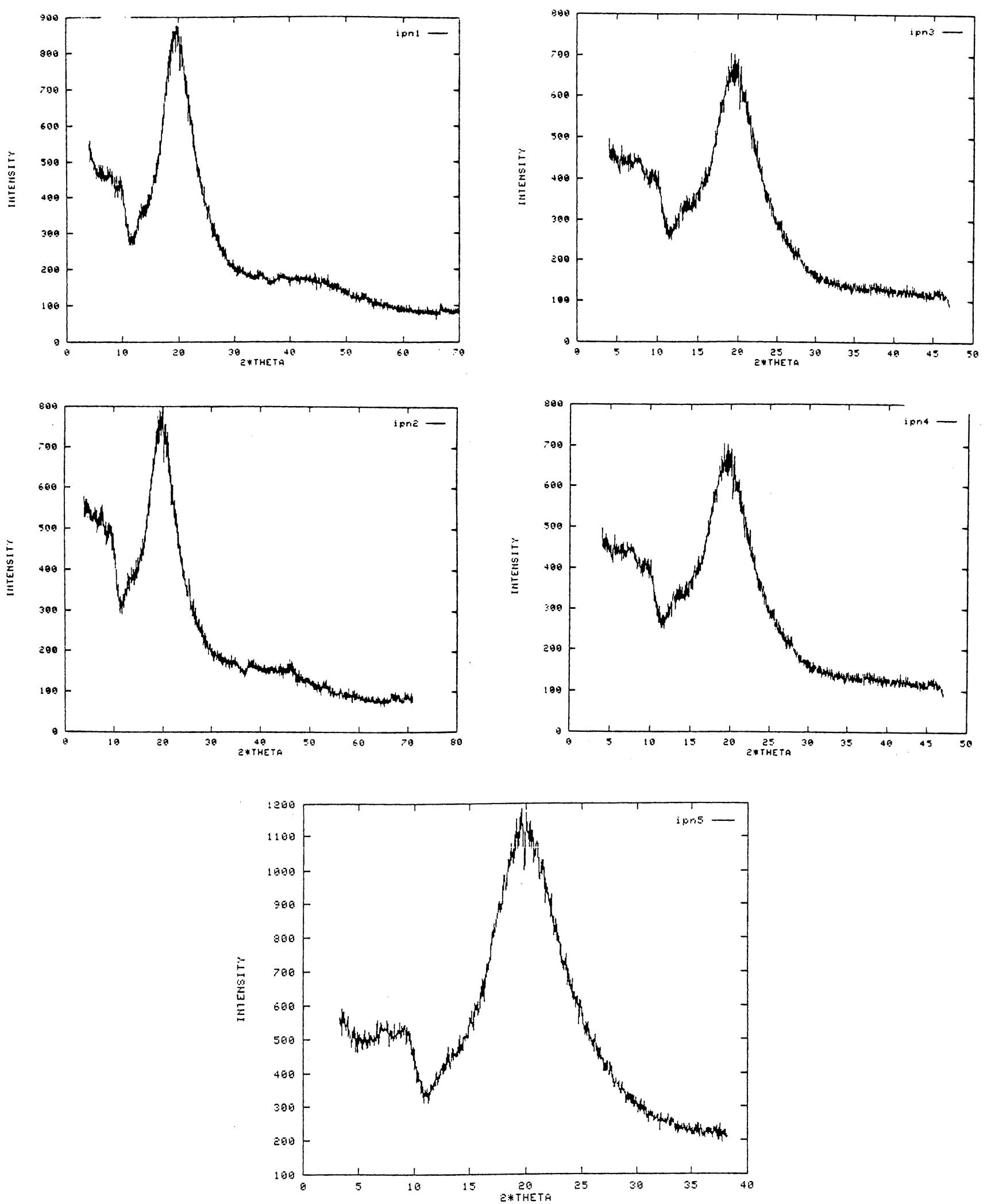

Figure 1. X-ray recording of samples $\mathrm{IPN}_{1}, \mathrm{IPN}_{2}, \mathrm{IPN}_{3}, \mathrm{IPN}_{4}$ and $\mathrm{IPN}_{5}$. 
Surface hardness of the IPNs (table 1) reflects the resistance to local deformation which is a complex property related to modulus strength, elasticity and plasticity. Surface hardness values lie in the range 81-92. Shore A surface hardness increases with increase in PAN percentage which is due to hard nature of PAN.

\subsection{Optical properties}

Results of diffuse light, total light transmittance and haze measurements are given in table 1 . These indicate that the
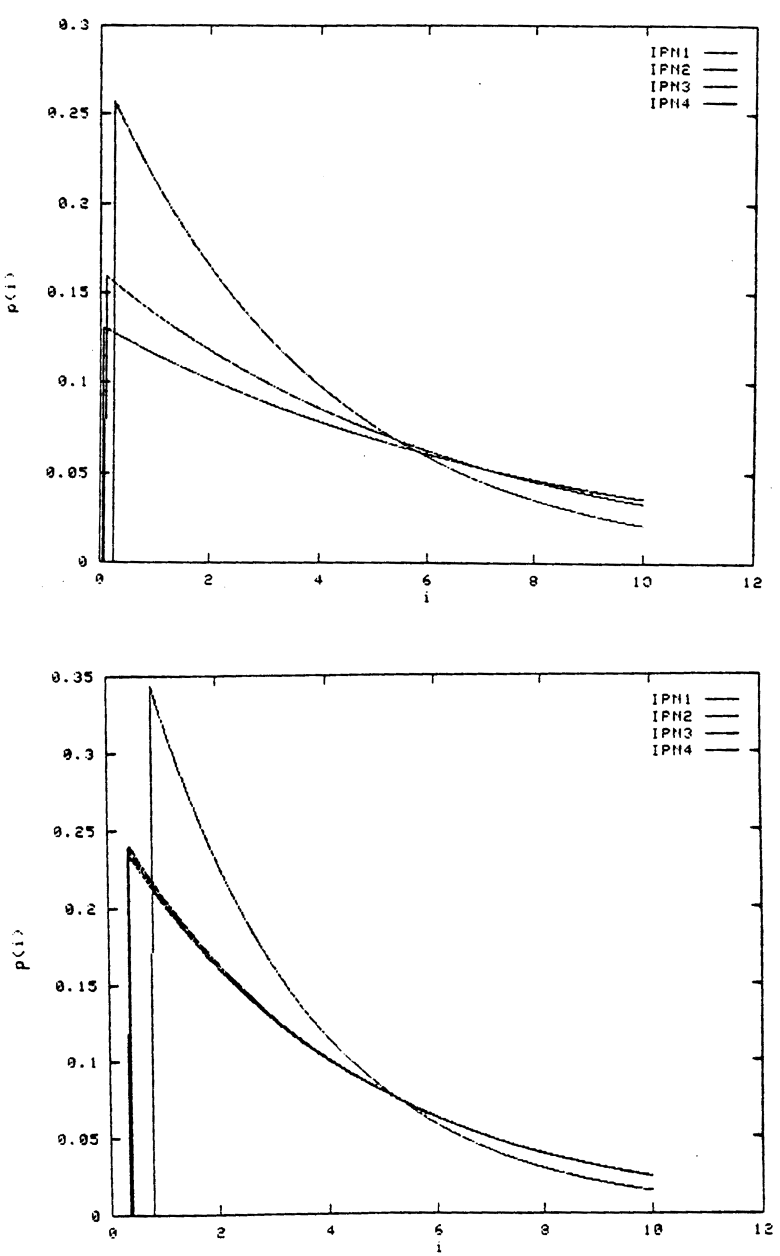

Figure 2. Crystal size distribution along (100) and (210) directions respectively. percentage of transmittance of light was very good in all IPN films and in the range 50.2-83.8\%. The difference is attributed to the variation in PU content of IPNs. The increase in PAN content of IPNs decreases the transmittance and increases percent haze. Comparison of optical properties of $100 \%$ PU, as well as $100 \%$ PAN component polymers indicate that $\mathrm{PAN}$ is a transparent film than polyurethane (castor oil + MDI), has transmittance around $43 \%$ depending on the levels of $\mathrm{NCO} / \mathrm{OH}$ ratios. Thus IPNs containing a low PU content are good transparent films with minimum haze percentage.

\subsection{Mechanical properties}

From the stress-strain curve, tensile strength, percent elongation at break, tear strength and initial modulus were tabulated in table 2. Tensile strength, tear strength and modulus increased with increasing acrylonitrile component, whereas, percent elongation decreased. It is probably because PAN is harder and brittle in nature. Interpenetration of PU as a separate phase in PAN brings about the enhanced modification in mechanical properties such as, tensile strength, tensile modulus and tear strength.

\subsection{X-ray profile analysis}

Table 3 gives the crystal size $(N)$ and lattice strain ( $g$ in $\%$ ) for two Bragg reflections (100) and (210). The crystal size for IPN $_{4}$ has a minimum value and this is also reflected in the observed maximum values of tensile strength, tear strength and tensile modulus for the same materials (see table 3 ).

The values of $\alpha^{*}$, the enthalpy obtained from crystal imperfection parameters, for different samples indicate a minimum for $\mathrm{IPN}_{3}$ showing that there is phase stabilization in this sample. In fact $\alpha^{*}$ implies physically that the growth of paracrystals in a particular material is appreciably controlled by the level of $g$ in the net plane structure.

It has been pointed out by Balzar and Ledbetter (1992) that Fourier analysis of the intensity profile gives surfaceweighted crystal size, whereas integral breadth method gives volume-weighted crystal size. The second derivative of the size coefficients is proportional to the surfaceweighted column-length distribution function and is given by

Table 1. Physico optical properties of PU/PAN IPNs.

\begin{tabular}{lcccc}
\hline $\begin{array}{l}\text { Sample } \\
\text { code }\end{array}$ & $\begin{array}{c}\text { Density } \\
(\mathrm{g} / \mathrm{cc})\end{array}$ & $\begin{array}{c}\text { Surface hardness } \\
\text { (shore A) }\end{array}$ & $\begin{array}{c}\text { Total percentage of } \\
\text { transmittance }\end{array}$ & $\begin{array}{c}\text { Percentage } \\
\text { of haze }\end{array}$ \\
\hline $\mathrm{IPN}_{1}$ & $45 \cdot 0$ & $5 \cdot 2$ & $50 \cdot 2$ & $89 \cdot 6$ \\
$\mathrm{IPN}_{2}$ & $47 \cdot 4$ & 11.6 & $59 \cdot 0$ & $85 \cdot 2$ \\
$\mathrm{IPN}_{3}$ & $58 \cdot 3$ & $15 \cdot 9$ & 74.2 & $80 \cdot 3$ \\
$\mathrm{IPN}_{4}$ & $65 \cdot 6$ & $11 \cdot 4$ & $77 \cdot 0$ & 81.7 \\
$\mathrm{IPN}_{5}$ & 68.5 & $15 \cdot 3$ & 83.8 & 78.6 \\
\hline
\end{tabular}


Table 2. Effect of PU/PAN composition on the mechanical properties of IPN.

\begin{tabular}{lcccc}
\hline $\begin{array}{l}\text { Sample } \\
\text { code }\end{array}$ & $\begin{array}{c}\text { Tensile strength } \\
(\mathrm{MPa})\end{array}$ & \% Elongation & $\begin{array}{c}\text { Tear strength } \\
\left(\mathrm{N} / \mathrm{mm}^{2}\right)\end{array}$ & $\begin{array}{c}\text { Tensile modulus } \\
(\mathrm{MPa})\end{array}$ \\
\hline $\mathrm{IPN}_{1}$ & 1.84 & 112.2 & 1.58 & 25.9 \\
$\mathrm{IPN}_{2}$ & 3.82 & 85.4 & 2.58 & 36.1 \\
$\mathrm{IPN}_{3}$ & 6.38 & 83.0 & 2.36 & 40.4 \\
$\mathrm{IPN}_{4}$ & $14 \cdot 16$ & 44.0 & 4.58 & 66.7 \\
$\mathrm{IPN}_{5}$ & 33.26 & 16.0 & 9.08 & 89.5 \\
\hline
\end{tabular}

Table 3. Microstructural parameter of PU/PAN IPNs.

\begin{tabular}{|c|c|c|c|c|c|c|c|c|c|}
\hline Sample & $\begin{array}{c}d_{h k l} \text { in } \AA \\
(h k l)\end{array}$ & $N$ & $P$ & $\begin{array}{c}g \\
(\%)\end{array}$ & $\begin{array}{c}\delta \\
(\%)\end{array}$ & $\alpha^{*}$ & $\begin{array}{l}D_{\text {surf }} \\
(\AA)\end{array}$ & $\begin{array}{c}D_{\mathrm{Vol}} \\
(\AA)\end{array}$ & Ratio \\
\hline \multirow[t]{2}{*}{$\mathrm{IPN}_{1}$} & $9 \cdot 208(100)$ & $7 \cdot 72$ & $0 \cdot 0687$ & $12 \cdot 45$ & $1 \cdot 3$ & $0 \cdot 34$ & 49.03 & $76 \cdot 94$ & $1 \cdot 56$ \\
\hline & $4 \cdot 487(210)$ & $4 \cdot 57$ & 0.4086 & $15 \cdot 32$ & $0 \cdot 7$ & $0 \cdot 33$ & $14 \cdot 14$ & $22 \cdot 20$ & 1.56 \\
\hline \multirow[t]{2}{*}{$\mathrm{IPN}_{2}$} & $9 \cdot 256(100)$ & $6 \cdot 36$ & 0.0954 & $13 \cdot 18$ & 1.4 & $0 \cdot 33$ & $40 \cdot 54$ & $63 \cdot 68$ & $1 \cdot 56$ \\
\hline & $4.454(210)$ & $4 \cdot 54$ & $0 \cdot 3625$ & $15 \cdot 17$ & $0 \cdot 7$ & $0 \cdot 32$ & $13 \cdot 53$ & 21.47 & 1.58 \\
\hline \multirow[t]{2}{*}{$\mathrm{IPN}_{3}$} & $9 \cdot 504(100)$ & $4 \cdot 14$ & $0 \cdot 2540$ & $12 \cdot 22$ & $1 \cdot 3$ & $0 \cdot 24$ & $26 \cdot 54$ & $46 \cdot 01$ & $1 \cdot 58$ \\
\hline & $4 \cdot 619(210)$ & $3 \cdot 72$ & $0 \cdot 8158$ & 14.83 & $0 \cdot 8$ & $0 \cdot 27$ & $13 \cdot 79$ & $18 \cdot 17$ & $1 \cdot 32$ \\
\hline \multirow[t]{2}{*}{$\mathrm{IPN}_{4}$} & $9 \cdot 504(100)$ & $4 \cdot 14$ & $0 \cdot 2540$ & $12 \cdot 22$ & $1 \cdot 3$ & $0 \cdot 24$ & $26 \cdot 54$ & $42 \cdot 01$ & $1 \cdot 58$ \\
\hline & $4 \cdot 521(210)$ & $4 \cdot 58$ & $0 \cdot 3566$ & $15 \cdot 39$ & $0 \cdot 9$ & $0 \cdot 32$ & 13.86 & $22 \cdot 00$ & 1.59 \\
\hline \multirow[t]{2}{*}{$\mathrm{IPN}_{5}$} & $9 \cdot 504(100)$ & $5 \cdot 13$ & $0 \cdot 1990$ & $11 \cdot 72$ & $1 \cdot 6$ & $0 \cdot 23$ & $33 \cdot 62$ & $53 \cdot 01$ & 1.57 \\
\hline & $4 \cdot 521(210)$ & $7 \cdot 54$ & 0.0563 & $13 \cdot 42$ & $1 \cdot 3$ & $0 \cdot 32$ & $22 \cdot 52$ & $35 \cdot 33$ & $1 \cdot 56$ \\
\hline
\end{tabular}

$$
P_{\mathrm{s}}(L) \alpha\left(\delta^{2} A_{\mathrm{s}}(n) / \delta L^{2}\right)
$$

and the volume-weighted column-length distribution function is given by

$$
P_{\mathrm{v}}(L) \alpha L\left(\delta^{2} A_{\mathrm{s}}(n) / \delta L^{2}\right), L=n d_{h k l}
$$

if the column-length distribution function is known, then the corresponding surface-weighted or volume-weighted crystal size is given by the integrals

$$
<D>_{\mathrm{s}, \mathrm{v}}=\frac{\int_{0}^{\infty} L P_{\mathrm{sv}}(L) \mathrm{d} L}{\int_{0}^{\infty} P_{\mathrm{sv}}(L) \mathrm{d} L} .
$$

This is a well known integral and can be evaluated. It has been found analytically that the ratio of $\langle D\rangle_{\mathrm{V}} \mid\langle D\rangle_{\mathrm{s}}$ is $T$ (3) and lies between 0 and 2 depending on the form of distribution function (Balzer and Ledbetter 1992). Using an exponential distribution function we have determined the surface weighted $\left(D_{\mathrm{s}}\right)$ and volume-weighted crystal sizes (table 3 ). The experimental ratio lies between 0 and 2 . The width of the crystal size distribution $(p)$ is also given in table 3. Figures 1 and 2 show the variation of crystal size distribution for different samples calculated from the observed two Bragg reflections (100) and (210), respectively. Along (100), the changes are quite significant but not so along (210) direction for different compositions of acrylonitrile component.

\section{Conclusions}

From the above studies we observe that:

(I) With increase in content of acrylonitrile the tensile strength, tear strength, and tensile modulus increases and this is due to decrease in the crystal size along the (100) direction.

(II) Phase stabilization, which is the consequence of the minimum value of the enthalpy $\left(\alpha^{*}\right)$, is observed in $n$ mixture of $50 \%$ of PU with $50 \%$ of acrylonitrile monomer (Sooryanarayana et al 1997).

(III) The crystal size distribution changes significantly along (100) direction with increase of concentration of acrylonitrile monomer.

(IV) Optical properties also show marked improvement with increase of acrylonitrile content.

These results indicate a structure-property relation in the castor oil based interpenetrating polymer network and this aspect has been quantified in terms of crystal imperfection parameters like crystal size and strain.

\section{Acknowledgements}

One of us (RS) thanks the JNCASR, Bangalore for a visiting fellowship. Authors thank $\mathrm{Mr}$ Soorya for X-ray recordings of the samples. 


\section{References}

Balzer D and Ledbetter H J 1992 J. Mater. Sci. Lett. 11 1419

Frisch H L, Klempher D and Frisch K C 1969 J. Polym. Sci. Part B 7775

Frisch H L, Frisch K C and Klempner D 1981 Pure Appl. Chem. 531557

Hindeleh A M and Hosemann R 1991 J. Mater. Sci. 265127

Hosemann R 1988 Prog. Coll. Polym. Sci. 7715

Hourston D J and Zia Y 1984 J. Appl. Polym. Sci. 29629

Naughton F C 1974 J. Am. Oil Chem. Soc. 5165
Patel M and Suthar B 1987 J. Appl. Polym. Sci. 342037

Patel P, Patel M and Suthar B 1988 Br. Polym. J. 20525

Press W, Flannery B P, Teakolsley S and Veeterling W T 1986 Numerical recipes (U.K.: CVP) p. 83

Siddaramaiah, Mallu P and Somashekar R 1998 J. Appl. Polym. Sci. 681739

Somashekar R and Somashekarappa H 1997 J. Appl. Crystal. 30 147

Sooryanarayana K, Somashekar R and Guru Row T N 1997 Solid State Ionics 104319

Sperling L H 1981 Interpenetrating polymer networks and related materials (New York: Plenum Press) 